Hannes Kröger and Rasmus Hoffmann

\title{
10 Who can realise their retirement plans? Poor health and employment crises as factors of exclusion
}

- A decline in industry-specific employment leads women, but not men, to expect their pension payments earlier

- Women with health problems are more strongly affected by employment decline in their retirement planning than women without health problems

- Healthy men and healthy women are affected by employment decline to a similar extent. Unlike men, women in poor health are particularly affected

\subsection{Health, employment crises, and plans for retirement}

In our study we investigate whether individuals are able to realise their plans for the timing of retirement. In particular we look at how poor health and the industry-specific relative decline in number of employees ('employment crisis') are related to the discrepancy between actual exit from the labour market and the expected start of pension payments. Such a discrepancy could arise either if a person retires earlier than planned or if he or she leaves the labour market before the beginning of planned retirement for any type of non-employment. The period before retirement is typically the first time in which health problems become so common and widespread throughout the population that health must be regarded as a potential factor leading to unintended early retirement. At the same time, decreasing sector-specific employment will make layoffs more likely, especially for those who are in poor health: an employment crisis should therefore be especially harmful to those individuals who are already less likely to be able to realise their plans for retirement.

Most research until now has examined the age of retirement (or early retirement) as the labour market outcome of interest. The expectations of the individuals in question play only a minor role. By focusing on the expectations of men and women before their retirement, we provide two new aspects to the literature discussing this phenomenon.

First, we treat retirement not as a single event, but as an important process and transitional phase in later life. It can be argued that, certainly in European 
societies, it is perhaps the single most important transition for older people. If we consider retirement to be a process, then our interest should not only be focused on the date of formal retirement, but on the timing of the actual exit from the labour market. If the formal date matches the expectations and planning of the first pension payments, but the last two years were spent in involuntary non-employment, then there is an obvious mismatch between the plan and the ability to realise that plan. This example would not be captured by a focus on formal retirement. It is therefore worthwhile to investigate the extent to which the retirement process can be planned by and is subject to the influence of individuals.

This leads to the second new aspect we contribute to the literature on retirement. We explicitly account for the plans that individuals make for the beginning of their retirement, and investigate whether those in poor health and those affected by an employment crisis are deprived of the ability to realise their plans. Unintended early retirement can have long-term consequences for potential material deprivation during retirement, and short-term consequences in the form of exclusion from the social network at the workplace.

Our definition of a plan for retirement is the age at which persons expect to collect their main pension. Using this definition, an individual's ability to actually realise their retirement plans is defined not by their private and perhaps impractical aspirations, but by a realistic plan conforming to the structures of the labour market, social norms, and the pension scheme in question. Unintended early retirement can have long lasting consequences for potential material deprivation during retirement and short-term consequences for the exclusion from the social network that is provided at work.

Our strategy for investigating the relationship between health, employment crisis - both separately and in interaction - and the discrepancy between retirement planning and exit from the labour market is divided in two parts.

First, we look at the association between health, employment crisis, and the age at which persons expect to collect their main pension. This should give us an indication as to whether or not persons adjust their expected retirement age according to their current health status and their expectations regarding future developments in employment in their industry.

We expect that persons with more reported health problems will plan to claim their pension earlier than healthy persons. On the other hand, any employment crisis that we record after persons report their expectations should not be related to their expected age of retirement, as it would represent a future decline in employment that should be hard to incorporate in their plans.

Second, we look at the association between health, employment crisis, and the risk of departure from the labour market when controlling for the expected start of pension payments. If an association remains, this means that either 
certain developments could not be foreseen or that the start of pension payments is only flexible to a certain degree, and cannot be completely adapted to individual health problems and the structural situation of the labour market, it is likely that both are the case. The analysis yields insights into the extent to which the start of retirement and pension payments can be planned. It also makes a comparison between an individual characteristic (health) and a structural determinant of the labour market situation (decline in employment) that is beyond the influence of the individual. The latter is harder to incorporate into retirement plans, because it would require the ability to project future economic development.

There already exists a great deal of evidence to support the claim that poor health leads to an earlier exit from the labour market (Griffin \& Hesketh 2008, Oksanen \& Virtanen 2012, Aranki \& Macchiarelli 2013).

Economic growth and unemployment have also been shown to influence retirement age (Börsch-Supan et al. 2009, Aranki \& Macchiarelli 2013, Riedel \& Hofer 2013). The decline in employment is an alternative measure that directly relates to the demand for labour in certain industries and is easier to measure on a sub-national level.

After taking into account the expected start of pension payments, it is possible that health no longer exhibits any association with drop-out from the labour market, because the influence of health on retirement behaviour is wholly commensurate with individuals' own expectations. It is less likely that individuals will be able to predict future developments regarding employment in their profession. Therefore, an employment crisis should be an important factor in limiting individuals' ability to realise their retirement plans. As individuals in poor health are the first that might be considered for redundancy or an early retirement scheme, this mechanism should be even stronger for those individuals.

Based on these considerations, we propose three hypotheses regarding labour market exit, in each case predicting the presence or absence of correlation when controlling for the expected age of pension collection. First, health does not influence the time of labour market exit. Second, an employment crisis leads to earlier labour market exit. Third, the impact of an employment crisis is stronger for those who are in poor health.

We differentiate in all our analyses between men and women, because their labour market trajectories are still very different in Europe. 


\subsection{Analytic strategy}

For the first part of the study, we conduct a simple linear regression of the expected age at the start of pension collection on health and future employment crisis. This allows us to estimate how many months earlier or later persons with health problems expect to receive their main pension compared to those who report no physical symptoms. The same goes for the degree of decline in employment, and for the interaction of the two.

In the second section we construct an event history data set. The analysis time is age and the event of interest is (final) departure from the labour market. We employ a log logistic hazard function for the survival analytical models; this function most closely mirrors the risk of labour market exit. The predictors are the same as in the first section. In addition, we control for the expected age of pension payment collection, early retirement plans, and the fear of not being able to work right up to retirement. The results can therefore be interpreted as being conditional on the expectations of the individuals.

One potential problem in our analyses is the fact that unobserved factors might result in a spurious correlation between poor health or employment crisis and exit from the labour market. We try to exclude as many alternative explanations for the association as possible by controlling for household composition, the economic and labour market situation, the characteristics of the expected pension, information on childhood health problems and socio-economic conditions, gender, age, education, and finally nationality in all our models. Table 10.1 gives an overview of the variables used and the SHARE questions they are based on.

In contrast to spurious correlation, reverse causality as an explanation for the association is, in our opinion, of minor importance. We can rule it out completely in cases of employment crisis, because the timing of an individual's labour market exit cannot affect the employment situation in a whole sector of the economy. It is also unlikely that the future timing of the exit will have a direct impact on the health status of the individual at the time of the first interview.

\subsection{Sample restrictions}

We restrict our sample to those SHARE participants who answered the question on expected start of pension payments in Wave 1 and who reported that they are either employed or self-employed at Wave 1. Respondents from Poland and the Czech Republic only entered the SHARE database at Wave 2, and thus their data begins in Wave 2. Our analyses only consider persons between the age of 50 and 
63 at the age of the first interview. This excludes all persons who retire unusually early or very late in life, since these extreme cases might be systematically different and warrant separate analyses. We want to draw conclusions principally for persons who retire in the normal age range between 50 and 70 . These restrictions leave a sample of 2,327 women and 2,772 men ${ }^{1}$.

We use the full information of the SHARE Waves 1-5. This allows us to observe respondents for a period of up to nine years in which enough labour market exits occur to split our sample by gender. This allows us to make more differentiated analyses, which is necessary because men and women have quite different career and retirement paths.

\subsection{Variables}

In the questionnaire for the SHARE Waves 1 and 2, the respondents are asked to state when they expect to collect different types of pension payments. The main pension is defined as the pension which has the highest wage replacement rate or, if this information is not available, the type of pension to which the individual has made the longest contribution. As a health measure we use the number of reported physical symptoms from a list of eleven possible physical health conditions. The overall number of reported health conditions allows us to distinguish between healthy individuals and those in poor health, which is an important characteristic of a health indicator for what is still a relatively young sample. The variable also has the advantage that it is self-reported, implying that individuals are aware of their problems, and can therefore take them into account according to their own perception of the severity of the health condition.

Employment crisis is measured as the decline in employment in per cent between the year of the interview and the year in which the person expects to collect their pension. If a person states that they expect to collect their pension after 2010, the decline is calculated for them between the year of the interview and 2010, as more recent data is not available from EUROSTAT. To increase the variance of the employment crisis indicator beyond the national level, we use information on decline in employment and self-employment by industry (NACE) in each country. This approach is useful, not only because it increases variance; different sectors of the economy have been affected to different degrees by the

1 Repeating the analyses without the sample restriction on age yields similar results; estimated associations are on average a little smaller, though. 
economic crisis. In addition, research has shown that early retirement is a mild form of downsizing, especially in industries that are in decline (De Preter et al. 2012). Furthermore, our data allow us to distinguish between external crisis indicators for employed and self-employed persons. Differentiating by country, industry, year, and type of employment ensures that the crisis indicators are as specific to the individual's labour market situation as possible. The data we use comes from EUROSTAT (last update by EUROSTAT in February 2014). For Switzerland, we use information from the Swiss national statistical office. To ensure that the employment crisis variable does not capture a long-term trend of gradual employment decline, but rather a new trend or crisis, we control for the decline in employment in the seven years before the first wave of SHARE.

Several of the variables from Table 10.1 contain missing information due to either dropout or non-response. To avoid excluding all cases with missing values on one of the covariates, multiple imputation via chained equations was done separately for men and women.

Table 10.1: Variables used in the study

\begin{tabular}{|c|c|}
\hline Dimension & Indicator \\
\hline Health & - Number of symptoms \\
\hline $\begin{array}{l}\text { Employment crisis } \\
\text { by country, industry, year, } \\
\text { employee/self-employed }\end{array}$ & $\begin{array}{l}\text { - Decline in employment between first wave and expected } \\
\text { age of pension, max. } 2010 \text { (per cent) } \\
\text { - Decline in employment in the seven years before first wave } \\
\text { (per cent) }\end{array}$ \\
\hline Household & $\begin{array}{l}\text { - Household size } \\
\text { - Partner } \\
\text { - Number of children } \\
\text { - Number of grandchildren }\end{array}$ \\
\hline Economic situation & $\begin{array}{l}\text { - Home owner } \\
\text { - Financial distress } \\
\text { - Log. household income } \\
\text { - Wealth }\end{array}$ \\
\hline Labour market situation & $\begin{array}{l}\text { - Log. income from employment } \\
\text { - Occupational group } \\
\text { - Effort-reward imbalance (upper third per country) } \\
\text { - Employed for more than one year } \\
\text { - Job satisfaction } \\
\text { - Job security } \\
\text { - Chances of advancement } \\
\text { - Partner in employment } \\
\text { - Industry sector }\end{array}$ \\
\hline
\end{tabular}


Table 10.1 (continued)

\begin{tabular}{ll}
\hline Dimension & Indicator \\
\hline & - Employee or self-employed \\
& - Level of responsibility \\
& - Labour force status \\
& - Public sector \\
& - Last labour market activity \\
& - Temporary employment \\
& - Bedridden for a month \\
& - Parents smoked \\
& - Sustained an injury \\
& - Number of books at home \\
& - Number of facilities at home \\
& - Skill level of parents (ISCO-88) \\
\hline Childhood information & - Country \\
& - Born in current country of residence \\
& - Years of education \\
& - Age \\
\hline Demography & - Public pension scheme \\
& - Plans early retirement \\
& - Fears that health might impede ability to work until \\
& retirement \\
& - Expected age to collect (main) pension \\
\hline Pension characteristics & releases 2.5 .0$, SHARELFE release 1.0 .0$, Wave 4 release \\
\hline
\end{tabular}

Source: SHARE Wave 1 and Wave2 releases 2.5.0, SHARELIFE release 1.0.0, Wave 4 release 1.1.1, Wave 5 release 0

\subsection{Results}

The results from the first part of the analysis are summed up in Table 10.2. It shows the association between, on the one hand, number of symptoms and decline in employment (in per cent) and, on the other, the expected start of pension payments (in months). Women expect to collect their pension earlier if they report symptoms of illness. Per additional symptom they expect to collect their pension approximately 0.8 months earlier, given a stable employment situation in their industry. This effect is relatively large, but the estimate has a high statistical uncertainty. However, in a model specification without the interaction term the coefficient of health symptoms is about 1.1 months in size and statistically significant, indicating that on average women with more symptoms actually expect to collect their pension earlier. Interestingly, a future decline in employment is 
also associated with an earlier-than-expected pension. Per one per cent decline in employment, women expect to collect their pension approximately 0.4 months earlier. A relevant interaction of the two variables could not be detected. For men, the associations are invariably negligible and the statistical uncertainty too high to infer any association at all.

Women seem to adjust their expected pension collection age more strongly than men. It is surprising that future developments in employment are associated with their expectations. That could either be because they actually (correctly) expect a downward trend or because workers in industries typically affected by employment crises tend to plan an earlier retirement anyway. Future research should investigate whether this pattern can be reproduced with alternative indicators or data.

The results of the analyses of labour market exit while controlling for expectations of the exit's timing (step 2) are presented in Table 10.3. Negative coefficients mean that exit from the labour market occurs earlier; positive coefficients mean that the exit occurs later. The models show only the coefficients of the number of symptoms, the employment crisis indicator, and their interaction. All models are controlled for the variables mentioned in Table 10.1. As the scale of the survival analytical models that is presented in Table 10.3 has no intuitive interpretation except for its sign, we calculated marginal effects for the interaction of health and employment crisis. These marginal effects are presented in Figure 10.1, and can be interpreted as the number of months that an individual retires earlier due to a one per cent decrease in employment, given a certain number of reported symptoms.

For women, there is a substantial association between the number of symptoms and their exit from the labour market. For every additional symptom a woman reports, she is predicted to leave the labour market three months earlier. In Figure 10.1 we can also see that the higher the number of symptoms, the stronger the association between an employment crisis and an early exit from the labour market is. Whereas women without any symptoms are expected to leave the labour market 0.21 months earlier given a one per cent decline in employment, women with five symptoms are predicted to leave the labour market more than 1.12 months earlier if their industry declines by the same degree. The interaction term is relatively large - about the same size as the main term of the employment crisis - indicating that the association between employment crisis and earlier exit from the labour market is roughly proportional to the number of symptoms. This is also represented in Figure 10.1 by the relatively steep rise of the marginal effects. Note, however, that the interaction term still contains a large degree of statistical uncertainty, because the decline in the employment variable has relatively little variance, as it can only be measured on the industry level, not on the individual level. This warrants a cautious interpretation of the results, and 
requires a replication with a larger sample, or an even longer period of observation, before a clear interaction can be established.

For men, the results are strikingly different. We can see no substantial association between health and exit from the labour market. An employment crisis does lead to an earlier exit from the labour market, although the interaction term is small, and statistical uncertainty for the estimates is too high to infer even a small association. In Figure 10.1 we can see that, for a low number of symptoms, the association between decline in employment and labour market exit is approximately the same for men as it is for women (between 0.3 and 0.4 months earlier for one or no symptoms). However, it is considerably smaller for a higher number of symptoms; for men predictions are practically zero.

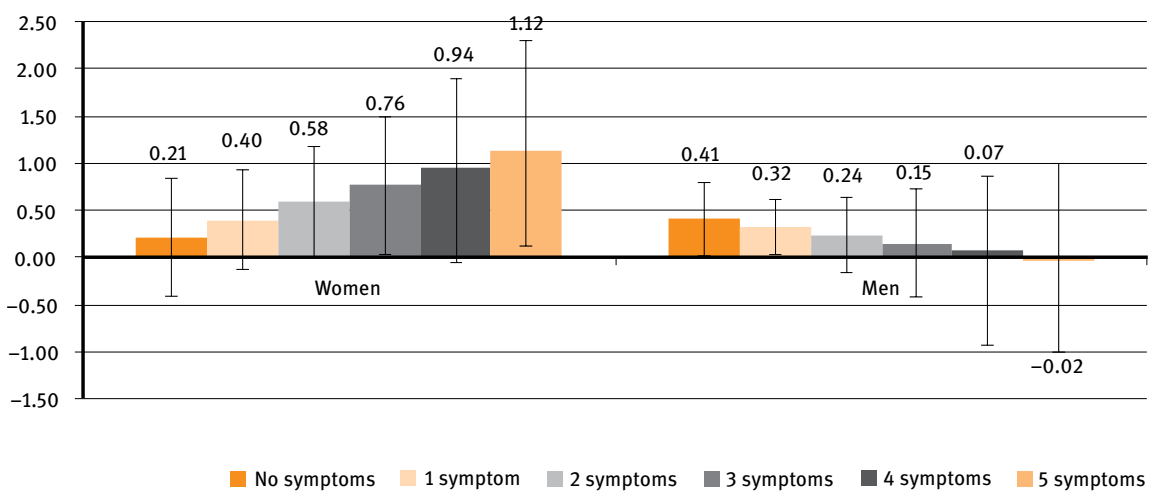

Figure 10.1: Effect of employment crisis on earlier exit from labour market by number of symptoms (in months)

Notes: $95 \%$-confidence interval shown, controlled for variables listed in Table 10.1, observations (men):2,772, observations (women): 2,327

Source: SHARE Wave 1 and Wave2 releases 2.5.0, SHARELIFE release 1.0.0, Wave 4 release 1.1.1, Wave 5 release 0 , authors' own calculations

It seems that, while employment crisis and health play an important role for women, even after taking their expectations about retirement into account, for men this is not the case at all for health and only to a lesser degree for decline in employment. A poor economic situation seems to be a strong factor preventing women from achieving their retirement goals, while men seem to have other options in the same situation. 
Table 10.2: Association between expected age of collection of main pension payments and health in Wave 1 and future employment crisis (in months)

\begin{tabular}{lllll}
\hline Variables & \multicolumn{2}{c}{ Women } & \multicolumn{2}{c}{ Men } \\
\hline & Coefficient & Standard error & Coefficient & Standard error \\
\hline Number of symptoms & -0.843 & $(0.532)$ & -0.0508 & $(0.0547)$ \\
\hline $\begin{array}{l}\text { Decline in employment } \\
\text { per cent) }\end{array}$ & $-0.431 * \star *$ & $(0.155)$ & -0.000504 & $(0.0088)$ \\
\hline $\begin{array}{l}\text { Interaction symptoms with } \\
\text { decline in employment }\end{array}$ & 0.0654 & $(0.0733)$ & 0.0039 & $(0.0066)$ \\
\hline \begin{tabular}{l} 
Observations \\
\hline
\end{tabular} & 2,327 & & & \\
\hline
\end{tabular}

Notes: Significance: ${ }^{\star \star \star}=1 \%$; ${ }^{\star \star}=5 \%$; ${ }^{\star}=10 \%$; Controlled for variables listed in Table 10.1 Source: SHARE Wave 1 and Wave2 releases 2.5.0, SHARELIFE release 1.0.0, Wave 4 release 1.1.1, Wave 5 release 0 , own calculations

Table 10.3: Survival model predicting labour market exit by health in Wave 1 and future employment crisis, controlling for expected pension age

\begin{tabular}{lllll}
\hline Variables & \multicolumn{2}{c}{ Women } & \multicolumn{2}{c}{ Men } \\
\hline & Coefficient & Standard error & Coefficient & Standard error \\
\hline Number of symptoms & $-0.0094^{\star \star \star}$ & $(0.0030)$ & -0.0024 & $(0.0029)$ \\
\hline $\begin{array}{l}\text { Decline in employment } \\
\text { per cent) }\end{array}$ & -0.00052 & $(0.00076)$ & $-0.0010^{\star \star}$ & $(0.00044)$ \\
\hline $\begin{array}{l}\text { Interaction symptoms with } \\
\text { decline in employment }\end{array}$ & -0.00046 & $(0.00034)$ & 0.00020 & $(0.00030)$ \\
\hline \begin{tabular}{lllll} 
Observations \\
\hline
\end{tabular} & 2,327 & & 2,772 & \\
\hline
\end{tabular}

Notes: Significance: ${ }^{\star \star \star}=1 \%$; ${ }^{* \star}=5 \%$; ${ }^{*}=10 \%$; Controlled for variables listed in Table 10.1 Source: SHARE Wave 1 and Wave2 releases 2.5.0, SHARELIFE release 1.0.0, Wave 4 release 1.1.1, Wave 5 release 0 , own calculations

\subsection{Health and employment crises are more important for women}

We have argued that the retirement process and the degree to which the individual can plan this should be seen as one dimension in which social exclusion can manifest itself in the life course. Empirically, we were able to show that exposure 
to an employment crisis leads women to adjust the expected start of their pension payments more strongly than men. In addition, women's ability to realise their plans is impeded considerably by poor health, particularly during an employment crisis. For men we find only a small association of decline in employment and labour market exit. From our analyses, we cannot say why these differences exist between men and women. One possible explanation could be that women are more often employed in less secure jobs. Another could be that, on average, households are less dependent on women's income, in which case the economic costs of an earlier-than-planned labour market exit are smaller for women than for men. It should also be kept in mind that an earlier exit from the workforce in a stressful economic situation and in poor health could be seen as a relief. Therefore, future research should investigate further whether earlier exits of women should be characterized as voluntary or involuntary. One step would be to compare single women to women in a relationship, and to investigate whether their patterns of labour market exit are similar, or whether single women more closely resemble the pattern observed in men.

\section{Acknowledgement}

This study was funded by a grant from the European Research Council: [ERC: 313532].

\section{References}

Aranki, Ted, Macchiarelli, Corrado (2013): “Employment duration and shifts into retirement in the EU”. In: ECB - Working Paper Series 1517.

Börsch-Supan, Axel, Brugiavini, Agar, Croda, Enrica (2009): “The role of institutions and health in European patterns of work and retirement". In: Journal of European Social Policy 19. No. 4, p. 341-358.

De Preter, Hanne, Mortelmans, Dimitri, Van Looy, Dorien (2012): "Retirement timing in Europe: does sector make a difference?”. In: Industrial Relations Journal 43. No. 6, p. 511-526.

Griffin, Barbara, Hesketh, Beryl (2008): "Post-retirement work: the individual determinants of paid and volunteer work". In: Journal of Occupational and Organizational Psychology 81. No. 1, p. 101-121.

Oksanen, Tuula, Virtanen, Marianna (2012): "Health and retirement: a complex relationship". In: European Journal of Ageing 9. No. 3, p. 221-225.

Riedel, Monika, Hofer, Helmut (2013): Determinants of the Transition from Work into Retirement. NRN working paper No. 2013-10. The Austrian Center for Labor Economics and the Analysis of the Welfare State, Linz: Johannes Kepler University. 
